$\xi=-1$

\title{
Online Education: the Academic Impact and Learning Effects
}

\author{
Saipunidzam Mahamad $^{1 *}$, Ahmad Sobri Hashim ${ }^{1}$ \\ ${ }^{I}$ Department of Computer and Information Sciences, Universiti Teknologi PETRONAS, 32610 Seri Iskandar, Perak, Malaysia \\ *Corresponding author E-mail: saipunidzam_mahamad@utp.edu.my
}

\begin{abstract}
Online education is a new way of learning which simplified many factors that affect student intake in higher institution. It gives opportunity to increase the level of education with or without going to the institution. Even though, there is an abundance of research pertaining to online education but very few of these research studies focus on the academic impact and learning effects of this modality on students. These paper present a review on academic impact and learning effects of online education. Educators and learners are benefited to explore beyond traditional classroom in many ways including development of technologies, social contribution and pedagogical.
\end{abstract}

Keywords: Online education; Academic impact; Learning effects; Globalisation.

\section{Introduction}

Online education is described as the creation and extension of the personal computer, the human acts includes globalization of contemplations, and the usage of development in exchanging musings and offering access to more people. The access to technology is very limited in the schools. Technology did not involve the use of computers as a whole which more concerned with media such as television programs and, education also using other media for teaching and learning in the classroom. Only in the early years of the 90 s and the 21 st century is a new technology-centric where computing and electronic media has disclosed and used in the next session of educator-student learning and teaching in schools similarly in higher institutions.

Educators are playing an important role in achieving the objectives of the online education which is lies not only on academic performance but also about the creativity and aesthetics. An educator is seen as a catalyst agent who also presented as comprehensive and integrated education. Duties include providing educators and knowledge to build the space and opportunity to develop students' interest in various fields. Educators also be seen as the task of forming the spiritual aspects of learning and teaching starting from childhood. The emergence of education technologies with appropriate learning approach could enhance the learning process that expose the young children to the technology while they learn from the lessons [1]. These children should be exposed to a variety of science in schools to build and generate their minds towards producing perfect human as the will of the state.

In the learning environment, technology offers both the educators and students the opportunity to explore patterns and situations of learning and teaching a new and meaningful. Various types of social interaction revealed and offered to give the information readily available. This can help educators and school administrators with the latest information, and can overcome some problems which are determined by space and time. In this era of technological development, the role of students has changed. Students can now build new materials, artefacts and new knowledge with the use of media that is not difficult to find.

Even in this century, technology explosion has occurred in almost every job in our daily lives, in the community, and at home, there are still schools that are lagging behind when mentioned to integrate technology in the classroom in terms of learning or teaching. Advances in technology if used properly can help educators and students acquire the complex skills and acquire knowledge based on high technology. Instructions to integrate technology in the classroom means more than teaching basic computing and software program but to teach how technology becomes a routine in achieving the goals of learning and teaching it. Technology is transparent and effective when it supports the goals of the curriculum, it is considered successful.

There is an abundance of research pertaining to online education but very few of these research studies focus on the academic impact and learning effects of this modality on students. In this paper, we present a review on academic impact and learning effects of online education. The section arranges by defining an online education includes online and distance learning, while academic impact and learning effects would include teaching and learning effectiveness. Emphasis is given to the role of Internet, connectivity and support needed for online education that will focus in the context of current developments.

\section{Literature Review}

Online education is a new instructional approach that join the learning division including educator with the learner barrier. The activities and courses are commonly offered by web learning stage, with some are passed on using elective developments that change non-traditional education, fuse the people who need to continue working throughout the day or raising families. These new technologies can facilitate greater cooperation, both with global partners and on a higher level. At the local level, the technology can support the drive for closer cooperation between institutions, combining the expertise and delivering greater critical. 
Various researchers define the general ways of online learning and its implementation. For example, Bates [2] interprets contemporary online education as an orchestrated training or learning that uses an extensive variety of headways to accomplish learners at a detachment and is expected to engage learner association and affirmation of learning. Meanwhile, Lockwood [3] gives another definition, he interconnects the online education and get ready result from the mechanical separation of educator and learner which frees the understudy from the need of wandering out to an adjusted place, at a settled time, to meet a settled individual, with a particular ultimate objective to be readied. From these definitions we can see that the students and educator are confined by space, yet not so much by time.

Online technology provides an opportunity to learn anywhere, anytime and from anyone. Sithole, Ikotun and Onyari [4] underlined the term evacuate learning has been associated with various instructional methods regardless of refinement is that the educator and the learner are separate in space and possibly time. This flexibility is important for non-traditional students and will allow a change in the involvement of higher education institutions in lifelong learning and continuous professional development. This will provide an important tool for the management to ensure that the diversity of that provision in the higher education system to meet the needs of all students. It also provides a platform to reach international markets and complement the existing development in cross border education.

The new mode has expanded the reach of higher education by creating more flexible and has many driven by the principles of equality, diversity, quality and efficiency. These principles remain at the heart of current developments. However, the landscape of open and distance learning has changed dramatically in recent years. Technological capabilities have grown with increasing rapidity by increasing the speed of access of information, interactivity and access to new technologies and the potential of the online platform. Digital materials replicated at low approach and almost no cost and more flexible copyright applies to the next. Connectivity has given us the chance to achieve anything at all over the world shows that there is a high chance for open institutions and online education.

\section{The Academic Impact and Learning Effects of Online Education}

\subsection{Role of Internet and Technology}

Information Technology is now so synonym with the life of mankind as it has various forms such as personal computers including desktops, laptop and smartphones. Things have become traditions in our lives is changing rapidly and no longer be able to overtaken by the user. Soeharto [5] gives the definition of education as a field of technology and ethics practiced to simplify and improve the effectiveness of teaching and learning through the production, use and management of resources and the appropriate technology.

The development of technology is something that is important for educators and indispensable as a means of teaching materials or for the educator. The use of technology is also described as an offshoot of proof to the success of the educator in the delivery of professionalism. However, there are still some educators who are reluctant to move in tandem with the development of technology in learning and teaching. They refused to raise the standard in the field and are not prepared to use technology in the classroom. Whereas students become more sophisticated, more intelligent in use of gadget which are now has become affordable or bought by parents. While the school was still not able to provide educators who are fully trained in education technology to help in delivering the IT.
Educational technology treated as a facilitator. Technological devices are constantly changing and many can access for free nowadays. The problem that arises is the time constraints for educators is online venture, the new proposals in the teaching and learning and also a variety of free programs that can be adopted to strengthen in school. Technological tools evolving rapidly lead users who are not already proficient in a product but also a new product introduced by emerging entrepreneurs or producers or programmers has undergone improvements. New educators who are born in the world of advanced technology can now use the advantages of the Internet to develop technology in education.

\subsection{Pedagogical}

The use of technology in education cannot be separated again in a world that is becoming more sophisticated. The use of a planned technology allows teaching and learning becomes more meaningful and effective. Educators need to have the skills to manage, use and evaluate the materials and tools such as software offered in the website. Pedagogy and technology used by educators now moving fast and always changing with the times. Technology in the classroom has become a necessity. Technology becomes a facilitator of the management class that belong to the delivery of learning and classroom. Technology also increase the desire to learn among students. Okojie, Olinzock and Okojie-Boulder [6] highlighted that technology with pedagogical education should not be separated as a single entity but should be integrated in the instructional delivery. Besides, technology education is defined as technical devices or aids used to help instruction by supporting the process that occurs in learning pedagogy.

However, there are some constraints in pedagogical issues related to the application of technology in the delivery of learning and teaching in schools. There are some schools struggling to integrate technology into existing curriculum. To change, it will take time, but time is always too fast in technology. For example, the user has just reached out to dominate the Web 2.0 software, but the passage of time has resulted in a fast new applications are introduced Web 3.0.

Watson, Watson and Reigeluth [7], initiate that the existence of dissatisfaction in today's education paradigm are increasingly questioning the standard that has been carried out by educators in particular and in general. Learner want an education system that is designed to meet the different requirements of today generation with some involvement of Information Technology. Learning and teaching should be new and transformative that allow customized learning which learning could be form in the format of what the students needed without move away from the syllabus

Shahneaz, Akhter and Yasmin [8] study and establish that people who integrate technology in learning approach increasing productivity for the second-two educators and also students. The development of an optimal teaching pedagogy and technology then go hand in hand like the analogy of a dance. Technology is mature, and a bit of colour tones in the melody. Pedagogical illustrated as dance choreography that creates a rhythm that is created by the melody. Together technology and pedagogy to shine and develop human creativity and responsiveness that allows us to study effectively and encouraging.

\subsection{Social}

These rapid changes had an impact and raise issues in the development of technology in the school with the use of computing technology. These issues are closely related to the application of technology in schools is still struggling to use it. Although there are obstacles such as anti-theft, anti-copying and security measures taken by the manufacturers but cannot prevent people from intelligent IT can access by hacking the password, or clone software involved. 
A world without limits sound interesting to expand the online learning capabilities. Internet or network are not restricted in terms of information and knowledge which contributed to social impact which involved students particularly. The information overflow disputed from the point reliability and validity of the information. The explosion of information brought to its discretion to make wise choices in the use of information received form the Internet. There is a good information and bad which need for filtering in certain aspect. Moreover, this could be the restraint that may be found in schools where there are some schools that do not have direct Internet connection. The facilities are not well establishing or install in some area especially in the villages or urban area. Not just that, problems also occur in some government institutions where disruptions such as weak server capabilities and slow network connection.

The technology has made everything in our fingertips. It allows latest information to be obtained at any time and any location by any desired user. With the availability of search engine such Google or Yahoo enable many websites connected produces information more useful. An expert has pointed out that the next generation will speed up the search process, organized systematically according to user preferences. The browser is being able to learn the user preferences accordingly through user browsing experiences. Its learned user's interest, save that information and display options that are more faithful to what the users want to search.

Social issues are not a hindrance because of the use of this software plagiarism feel that they do not impact on the social and economic. Though having a generation of computer users and software that has a high ethical standard in respect of these issues. Educators play an important role in this regard. Educator's model ethical behaviour is high. This means that educators be the catalyst that brings the issues of piracy and the use of counterfeit software on the impact and consequences to students.

It is a human nature to be attracted to any appealing things and same goes to education institution students as well. Students at any age are attracted to fun and new activities using new technologies. With the technology new learning concept could be applied and it is practical to implement this learning environment for that age group using the ever appealing advance devices. To be succeed in academic, a learning process are requiring to include both involvement of teachers and learners. The recent technologies have the potential to influence in many learning aspect, but educator alone will minimize the abilities of the online learning approaches. O'Neil and Perez [9] highlighted the importance of understanding the relationship among learner and educator, if new technologies are to be implemented successfully. Each participation needs to be identified and accommodated clearly. It includes different learning activities to support learners, teachers, and parents at different stages of implementation, starting with those that account for the skills and capabilities of all the participants at early stages, moving through to later activities that rely upon wider and deeper operational [10].

\section{Conclusion}

The online education has given impact especially on instructional approach. The issues involving the application of technology, it is important is that educators are been provided with the knowledge and basic technology skills to support learning and development. The integration of technology into the curriculum had not emphasized as an important component of instruction in the learning process.

Technology integration skills in teaching and learning technology is meant for educators to develop teaching strategies to motivate students due to the students will need to face the variety of learning phases. They need to be sensitive and wise use of software and electronics-based technologies in designing instruction. Educators need to use technology to be used and evaluated as a relevant technology in education.

\section{References}

[1] Mahamad, S., Kaoemanee, Y., Ibrahim, M., and Kasbon, R., A flash-based framework for learning Thai language as second language in preschool education. Software engineering and knowledge engineering: Theory and practice, 2012, pp.115-122.

[2] Bates, A., Instructional design for distance learning. Instructional Design: International Perspectives II: Volume I: Theory, Research, and Models: volume Ii: Solving Instructional Design Problems, 2014, pp. 369.

[3] Lockwood, F., Open and distance learning today. Routledge. 2013.

[4] Sithole, K., Ikotun, B. D., and Onyari, E. K., Influence of generations' traits on teaching and learning in an open distant learning (ODL) environment, 2012

[5] Soeharto, K., Analisis Interpretasi Elit Pendidikan Indonesia tentang Ideologi Pendidikan Nasional. Jurnal Pendidikan dan Pembelajaran (JPP), 17(1), 2012, 68-81.

[6] Okojie, Mabel CPO, Anthony A. Olinzock, and Tinukwa C. Okojie-Boulder, The Pedagogy of Technology Integration. The Journal of Technological Studies, 2015.

[7] Watson, W. R., Watson, S. L., and Reigeluth, C. M., Education 3.0: Breaking the mold with technology. Interactive Learning Environments, 23(3), 332-343, 2015.

[8] Shahneaz, M. A., Akhter, S., and Yasmin, N., The Impact of Teacher and Technology in Class Room. learning, 4, 5. 2014

[9] O'Neil, H. F., \& Perez, R. S., Web-based learning: Theory, research, and practice. Routledge. 2013.

[10] Passey, D., Mobile learning in school contexts: can teachers alone make it happen? IEEE Transactions on Learning Technologies, 3(1), 68-81. 2010 . 